\title{
DESCONSTRUIR PARA CONSTRUIR: PERCEPÇÃO DE INTEGRANTES DE UM GRUPO DE GESTANTES SOBRE BOAS PRÁTICAS OBSTÉTRICAS
}

\author{
Giovana Luiza Rossato ${ }^{1}$; Leandro da Silva de Medeiros ${ }^{2}$; Lucas Muller \\ Brunelli ${ }^{3}$; Lisiele Marin Roath ${ }^{4}$, Giovana Padoin Brutti ${ }^{5}$; Andressa Caetano da \\ Veiga $^{6}$; Dirce Stein Backes ${ }^{7}$
}

\section{RESUMO}

Objetivo: Conhecer a percepção de integrantes de um grupo de gestantes sobre as boas práticas de atenção ao parto e nascimento. Metodologia: Trata-se de uma pesquisa exploratório-escritiva, de abordagem qualitativa, realizada entre janeiro e março de 2021. Participaram do estudo 25 integrantes de um Grupo de Gestantes, por meio de entrevistas com questões norteadoras, realizadas pela plataforma remota "ZOOM". Resultados e Discussões: Da análise dos dados emergiram duas categorias temáticas: Desaprender para aprender; e Do querer à transformação. Conclusão: A percepção de integrantes de um grupo de gestantes sobre as boas práticas de atenção ao parto e nascimento está relacionada às relações interprofissionais e, sobretudo, à superação do modelo verticalizado de intervenção nas práticas obstétricas. É preciso, para tanto, desmistificar crenças, superar práticas intervencionistas desnecessárias e transcender barreiras impostas pelo modelo hegemônico de intervenção obstétrica.

Palavras-chave: Equipe de Assistência ao Paciente; Humanização de Assistência ao Parto; Pesquisa Qualitativa; Saúde Materno-infantil.

Eixo Temático: Atenção Integral e Promoção à Saúde (AIPS).

\footnotetext{
${ }^{1}$ Estudante do Curso de Enfermagem, Universidade Franciscana. Membro do Grupo GESTAR.

E-mail: giovana.rossato@ufn.edu.br

${ }^{2}$ Estudante do Curso de Enfermagem, Universidade Franciscana. Membro do Grupo GESTAR.

E-mail: leandro.medeiros@ufn.edu.br

${ }^{3}$ Estudante do Curso de Enfermagem, Universidade Franciscana. Membro do Grupo GESTAR.

E-mail: lucasmb24@gmail.com

${ }^{4}$ Estudante do Curso de Enfermagem, Universidade Franciscana. Membro do Grupo GESTAR.

E-mail: lisiele.marin@ufn.edu.br

${ }^{5}$ Estudante do Curso de Enfermagem, Universidade Franciscana. Membro do Grupo GESTAR.

E-mail: giovana.pbrutti@ufn.edu.br

${ }^{6}$ Fisioterapeuta. Aluna do Mestrado Profissional em Saúde Materno Infantil da Universidade Franciscana - UFN. E-mail: andressacveiga@gmail.com

7 Doutora em Enfermagem. Professora do Curso de Enfermagem e do Mestrado Profissional em Saúde Materno Infantil da UFN. E-mail: backesdirce@ufn.edu.br
} 


\section{INTRODUÇÃO}

As boas práticas de atenção ao parto e nascimento foram descritas, inicialmente, em 1996, pela Organização Mundial de Saúde (OMS) e, atualizadas, em 2018. Essas são práticas comuns determinadas para a condução do processo de parturição, baseadas em evidências científicas, com a finalidade de estabelecer cuidados adequados e seguros para a mulher e assegurar a qualidade da assistência materno-infantil (WHO, 2018).

A busca pela qualidade da atenção em saúde materno-infantil é uma temática recorrente e discutida nos diferentes espaços e contextos da saúde. Dentre as diversas condutas e prospecções, destaca-se a Rede Cegonha, instituída no Sistema Único de Saúde (SUS), no ano de 2011. Esta dispõe de prerrogativas que asseguram o direito da mulher para ter um planejamento reprodutivo e atenção humanizada durante o pré-natal, parto e puerpério. Esta assegura, ainda, cuidados efetivos às crianças desde o nascimento seguro, crescimento e desenvolvimento saudável (BRASIL, 2011).

Qualificar a assistência materno-infantil é fator preponderante para prospectar o desenvolvimento humano e social de forma saudável e sustentável. Considerando a importância de observar cada pessoa dentro de suas especificidades e trabalhar a partir dessas, percebe-se que intervenções humanizadas que considerem o binômio mãe-bebê são cada vez mais estimuladas. Além disso, o comprometimento profissional no que se refere ao acolhimento com respeito e dignidade, bem como os cuidados resolutivos são cada vez mais estimulados (ARAÚJO et al., 2019).

As boas práticas, com base em novos referenciais e evidências científicas, foram classificadas com vistas à orientação nas condutas do profissional. As mesmas são assim consideradas: práticas claramente úteis e que devem ser estimuladas; práticas claramente prejudiciais ou ineficazes e que devem ser eliminadas; e práticas usadas de modo inapropriado no momento de trabalho de parto e parto. Nessa direção, o estudo demonstra que no Brasil, as boas práticas durante o trabalho de parto acontecem em menos de 50\% das mulheres, demonstrando a premente necessidade de avançar na superação de modelos tradicionais (ROCHA et al., 2017). 
Dentre as metas dos Objetivos do Desenvolvimento Sustentável (ODS), definidas para o ano de 2030, figura a redução de 70 mortes por 100.000 nascidos vivos e acabar com as mortes evitáveis de recém-nascidos e crianças menores de 5 anos (OPAS, 2021). Esta meta somente será atingida, por meio de esforços coletivos pautados em novos saberes e práticas, sustentadas em evidências científicas.

Considerando a importância das boas práticas de atenção ao parto e nascimento, preconizadas pela OMS e contempladas na Agenda de Prioridades de Pesquisa do Ministério da Saúde, mais especificamente no Eixo 14 - Saúde Materno Infantil (BRASIL, 2018), obejtivou-se, conhecer a percepção de integrantes de um grupo de gestantes sobre as boas práticas de atenção ao parto e nascimento.

\section{METODOLOGIA}

Trata-se de uma pesquisa qualitativa, de caráter exploratório-descritiva. A pesquisa qualitativa se traduz em "expressões e significados que as pessoas dão a suas experiências e vivências. Todos têm como parâmetro o reconhecimento da subjetividade, do simbólico e da intersubjetividade nas relações, e trazem para o interior das análises [...]" ( MINAYO, 2017, p. 16).

Fizeram parte deste estudo 25 integrantes de um Grupo de Gestantes GESTAR, dentre os quais, 12 acadêmicos da área da saúde, 6 enfermeiros, 2 médicos, 3 gestantes e 2 puérperas. O grupo GESTAR foi criado em 2016 e comtempla estudos e discussões sobre a gestação, parto, puerpério e outras temáticas de interesse das usuárias de saúde. Antes da pandemia, o GESTAR encontrava-se, quinzenalmente, com base em cronograma de atividades semestrais. Atualmente, o mesmo realiza encontros virtuais através da Rede Social Instagram e Plataforma Google Meet. Bem como, intensa atividade nas Redes Social Instagram e Facebook com postagens promovendo Boas Práticas em Saúde Materno-infantil.

Os critérios de inclusão dos participantes foram: ter mais de 18 anos, ser participante dos eventos promovidos pelo grupo GESTAR, ser pesquisador ou acompanhante das postagens nas redes sociais Instagram e Facebook sobre 
diversas temáticas relacionadas à saúde materno-infantil e aceitar participar da pesquisa.

Após o aceite, os entrevistados foram informados que a sua participação seria voluntária e foram esclarecidos sobre os direitos da sua desistência em qualquer momento da pesquisa. O sigilo dos dados fornecidos foi assegurado e informado que os resultados do estudo seriam apresentados em eventos e publicados em revistas científicas. A identificação dos (as) participantes foi feita a partir das iniciais A (acadêmicos), $E$ (enfermeiros), M (médicos), G (Gestantes) e $P$ (puérperas) do número na ordem do texto (A1, E1, M1, G1, P1.).

A coleta de dados se deu entre janeiro e março de 2021, por meio da plataforma remota (Zoom), mediante a técnica de entrevistas com questões norteadoras abertas, no sentido de possibilitar a interação entre pesquisadores e participantes. Favoreceu-se, dessa forma, a contextualização de experiências, vivências e perspectivas que contribuíram para esclarecer a problemática da investigação.

Todos os aspectos éticos foram respeitados ao longo do processo de pesquisa. O presente estudo tem parecer favorável do Comitê de Ética em Pesquisa (CEP) sob o número de protocolo: 4.253.922.

\section{RESULTADOS E DISCUSSÕES}

Da análise dos dados emergiram duas categorias temáticas: Desaprender para aprender; e Do querer à transformação, conforme detalhamento descritivo, a seguir:

\subsection{Desaprender para aprender}

Em seus depoimentos, os participantes analisaram a necessidade de desconstrução pessoal, profissional e cultural nas suas práticas de trabalho frente às gestantes e puérperas. Demostraram que as boas práticas em saúde maternoinfantil fomentam o cuidado singular e multidimensional.

Compreende-se que o fluxo de atendimentos nas unidades de saúde são estabelecidas com horários fixos. Ele consiste em uma organização a partir de um padrão repetível e sequencial, ou seja, com rotina de consultas pré-estabelecidas. 
No entanto, sabe-se que os horários da gestante e sua família são preenchidos com outras atividades, e podem apresentar dificuldades no comparecimento das consultas durante o pré-natal. Conforme demostrado na seguinte fala, alternativas na organização dos atendimentos podem ter mais êxito na acessibilidade das famílias que estão à espera de um bebê:

Meu horário (de trabalho) é das 8 horas às 4 horas às 5 horas da tarde, tá mas porquê que eu não posso fazer de noite que o horário que todo mundo pode fazer uma videochamada, que daí traz essas mulheres para junto e ela consegue então se sentir acolhida, se sentir mais segura e não só na consulta naqueles horários estipulados pela equipe, mas pensando na família também (E1).

Com base nisso, DORICCI e GUANAES-LORENZI (2020) reforçam que o funcionamento das unidades de saúde tenham horários flexíveis de acesso à população. A Política Nacional de Atenção Básica (PNAB) recomenda a possibilidade de horários ajustáveis, desde que não comprometa as demandas da comunidade (BRASIL, 2017). Além disso, consonante com a fala anterior, a realização de consultas virtuais é uma ferramenta facilitadora e necessária. Mostrouse muito útil durante a pandemia da COVID-19 e possibilita o acompanhamento, esclarecimento e orientações para as gestantes e puérperas (MACHADO et al, 2021).

Analisou-se, sob outro ângulo, a disposição dos profissionais quanto a reconstrução dos seus saberes e práticas dentro do seu trabalho. Comprende-se que os avanços na área da saúde são frequentes e, para isso, as práticas profissionais necessitam ser revistadas e analisadas de tal modo que reflita na qualidade prestada aos usuários. Para tanto, é fundamental que as novas informações tenham sentido para os envolvidos, bem como estes precisam estar sujeitos a aprender e desaprender condutas, conhecimentos e comportamentos. Conforme percebido na seguinte fala.

Eu fiquei meio assim sabe, porque eu tinha aprendido diferente, tive que desaprender para aprender de novo (M1).

Os profissionais de saúde que atendem às mulheres durante o período gravídicopuerperal tem a responsabilidade de organizar atendimentos que proporcionem 0 melhor para elas, fortalecendo sua autonomia e respeitando sua singularidade (NASCIMENTO et al., 2020). Na fala, a seguir, evidencia-se a relevância de espaços 
ampliados de discussão e reflexão sobre a prática profissional, a qual não pode se dar de forma pontual e linear:

Parte desde a atenção do profissional, como eu recebo essa mulher, minha comunicação não-verbal, me preparando para atender essa mulher, sem colocar os meus valores na frente do meu cuidado que é diferente eu posso ter valores totalmente diferente daquela família mas nem por isso eu posso deixar com que isso invado meu cuidado eu tenho que ser neutra em relação a isso (E2).

\subsection{Do querer à transformação}

O processo de mudança baseia-se em estar aberto para receber o que for necessário, a fim de aperfeiçoamento nas ações pessoais e profissionais. No entanto, para tal mudança é indispensável o acesso às informações apropriadas que contribuam em determinada tomada de decisão. Visto que, para muitas gestantes escolher como será a via do parto é uma das decisões mais importantes, e para tal, necessita de muito empoderamento e conhecimento (GOMES et al., 2017).

Percebe-se no seguinte discurso que a falta de orientação profissional não colaborou com a vontade da gestante de tentar realizar o parto normal, mas insegurança na sua escolha:

Eu tinha ideia de tentar parto normal, mas ao mesmo tempo me sentia muito insegura por não ter tantas informações e ter tanta apoio da minha médica (G1).

No que se refere às orientações quanto a escolha do parto, destaca-se o plano de parto. Este caracteriza-se como documento em que a gestante registra as suas vontades em relação ao parto e quais procedimentos não gostaria que fossem realizados, evitando situações constrangedoras e desnecessárias. É um instrumento que beneficia a gestante e o profissional responsável, pois terá esclarecida cada técnica que será realizada. Além disso, a gestante vai ter mais controle sobre o seu corpo e o nascimento do bebê (SILVA et al., 2017).

As orientações profissionais à mulher, no período gravídico-puerperal, devem ser efetuadas com responsabilidade e promissoras de saúde. De acordo com Marques et al (2021, p.6) "o pré-natal às gestantes e a família devem receber orientações fundamentais para uma adequada atenção ao pré-natal, puerpério e cuidados com o recém-nascido". Nesse sentido, reforçar cuidados para as mulheres auxilia na sua saúde e do seu bebê, transformando-os em protagonistas da sua trajetória. 
O, mãezinha é bom tu pegar e ir numa nutricionista, ir fazer uma fisioterapia, essas dicas, faltou um pouquinho de dicas assim: olha mãe se tu quiser ir numa nutricionista é legal tu ir, ou tu quer fazer fisioterapia ou atividade física é recomendada[...] Oh mãe, se tu quer fazer pilates tu pode fazer, faça, ah tu quer cuidar da alimentação pode ir em uma nutricionista, mais dicas e mais informações (G2).

A qualificação profissional, figura como um outro elemento fundamental no fomento das boas práticas obstétricas. Destaca-se, nesse processo, a enfermagem obstétrica, formação específica na prestação de uma assistência integral e qualificação ao binômio mãe-bebê. A participação desse profissional pode garantir que o equilíbrio entre intervenções desnecessárias e o processo fisiológico do parto sejam adequadas evitando, assim, que as mulheres não passem por situações traumáticas sem motivos. (SANTOS et al, 2019).

Eu mudei muito a minha forma de pensar e meus conceitos, foi quando eu me incluí com a turma de enfermagem obstétrica, a residência. Eu pensei muito, a gente é uma equipe, né, eu não estou lá em cima, então começamos a trabalhar na mesma linha e acho que por isso me empoderei, sabe, porque eu vi que tinha a pessoa do meu lado. Percebi que a mudança traz muito sofrimento, mas depois te empodera e acho que isso falta nos obstetras (M2).

Se eu fosse a enfermeira dessa unidade, já tendo os dados dela, eu faria a busca pra ela fazer o acompanhamento correto para não haver intercorrências no parto e prevenir a transmissão vertical para o feto (E3).

Por isso, além de querer mudar é necessário entrar em conformidade com outras estratégias, ou seja, construir caminhos integrados com trabalho multiprofissional na assistência obstétrica. Visto que, colabora na oferta de autonomia para a mulher. Além disso, possibilita fortalecer melhores condições na rede de saúde (MEDEIROS; SANTOS; MENEZES, 2021). Promovendo, assim, qualidade no atendimento e o empoderamento feminino.

\section{CONCLUSÃO}

A percepção de integrantes de um grupo de gestantes sobre as boas práticas de atenção ao parto e nascimento está relacionada às relações interprofissionais e, sobretudo, à superação do modelo verticalizado de intrvenção nas práticas obstétricas. É preciso, para tanto, desmistificar crenças, superar práticas 
intervencionistas desnecessárias e transcender barreiras impostas pelo modelo hegemônico de intervenção obstétrica.

O estudo reforça a necessidade de trabalhar cada vez mais as boas práticas ao parto e nascimento nos diversos âmbitos da saúde, bem como repensar sobre a atenção obstétrica, a fim de garantir o acesso, acolhimento, resolutividade e protagonismo da mulher em suas múltiplas dimensões.

Defende-se, a partir do estudo, a ampliação de espaços de discussões em ambientes de ensino acerca da temática das boas práticas de atenção ao parto e nascimento. Aos profissionais de saúde, ações de educação permanente para que compreendam a necessidade de utilizar práticas, no qual respeitem a autonomia da gestante, escutem suas vontades, acolham as suas inseguranças, propiciando um parto conforme foi almejado pela mulher.

Os resultados desta pesquisa demonstram que as boas práticas de atenção ao parto e nascimento, aliadas a formação dos estudantes e profissionais da saúde, sobretudo, no ensino, podem contribuir para a mudança de paradigmas no cenário obstétrico. Dessa forma, esta pesquisa pode subsidiar outros estudos na área obstétrica, a fim de qualificar a gestão e atenção à saúde materno-infantil.

\section{AGRADECIMENTOS}

O presente trabalho foi oriundo do Programa Institucional de Bolsas de Iniciação Científica da Universidade Franciscana (PROBIC/UFN).

\section{REFERÊNCIAS}

ARAÚJO, I. C. F. G. et al. Qualidade do parto e impacto nos indicadores da saúde da criança. Revista Ciência Plural, v. 5, n. 1, p. 18-33, 5 jun. 2019.

BRASIL. Ministério da Saúde. Gabinete do Ministro. Portaria № 1.459, de 24 de Junho de 2011. Institui, no âmbito do Sistema Único de Saúde - SUS - a Rede Cegonha. Diário Oficial da União, Brasília, DF, 24 jun. 2011.

BRASIL. Ministério da Saúde. Portaria № 2.436, de 21 de Setembro De 2017. Brasília, 2017.

BRASIL. Ministério da Saúde. Ministério da Saúde reforça cuidados maternoinfantis no SUS. Brasília, DF: MINISTÉRIO DA SAÚDE, 2020. 
BRASIL. Ministério da Saúde. Secretaria de Ciência, Tecnologia e Insumos Estratégicos. Departamento de Ciência e Tecnologia. Agenda de Prioridades de Pesquisa do Ministério da Saúde - APPMS [recurso eletrônico]. Brasília: Ministério da Saúde, p. 26, 2018.

DORICCI, G. C. e GUANAES-LORENZI, C. Aspectos contextuais na construção da cogestão em Unidades Básicas de Saúde. Rev. Saúde em Debate. 2020, v. 44, n. 127.

GOMES R.P.C. et al. Plano de parto em rodas de conversa: escolhas das mulheres. REME - Rev Min Enferm. 2017, $21: e-1033$.

MACHADO, F. C., et al. Teleorientação com o uso de ferramentas digitais no auxílio ao atendimento odontológico em época de pandemia da COVID-19: Revisão integrativa da literatura. Research, Society and Development, 2021, 10(6).

MARQUES, B. L. et al. Orientações às gestantes no pré-natal: a importância do cuidado compartilhado na atenção primária em saúde. Universidade Federal da Fronteira Sul (UFFS), 2019. Escola Anna Nery [online]. 2021, v. 25, n.1

MEDEIROS, M. P. S.; DOS SANTOS, R. A.; MENEZES, M. O. Interface multiprofissional para implementação do protocolo de parto seguro. Caderno de Graduação - Ciências Biológicas e da Saúde - UNIT - SERGIPE, [S. I.], v. 6, n. 3, p. 135, 2021.

MINAYO, M. C. S. Cientificidade, generalização e divulgação de estudos qualitativos. Ciência \& Saúde Coletiva, Rio de Janeiro, v.22, n.1, p.16-17, 2017.

NASCIMENTO, E. R. et al. Desafios da assistência de enfermagem ao parto humanizado. Caderno De Graduação - Ciências Biológicas e da Saúde - UNIT SERGIPE, v. 6, n.1, p. 141-146, 2020.

OPAS. Organização Pan-Americana da Saúde. Objetivos de Desenvolvimento Sustentável. Brasília, DF: OPAS, 2021. Disponível em: https://www.paho.org/bra/index.php?option=com_content\&view=article\&id=5849:obje tivos-de-desenvolvimento-sustentavel\&Itemid=875. Acesso em: 5 mar. 2021.

ROCHA, F. R. et al. Análise da assistência ao binômio mãe-bebê em centro de parto normal. Cogitare Enfermagem, [S.I.], v. 22, n. 2, abr.. 2017.

SANTOS, F. A. P. S. et al . Autonomia do enfermeiro obstetra na assistência ao parto de risco habitual. Rev. Bras. Saude Mater. Infant., Recife, v. 19, n. 2, p. 471-479, jun. 2019

SILVA, A. L. N. V. et al. Plano de parto: ferramenta para o empoderamento de mulheres durante a assistência de enfermagem. Revista de Enfermagem da UFSM, v. 7, n.1, 144 - 151, 2017. 
EDUCAÇÃO, SAÚDE

ETECNOLOGIA

26 A 28 DE OUTUBRO DE 2021

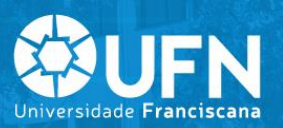

WHO. World Health Organization. Recommendations: intrapartum care for a positive childbirth experience. Geneva: WHO, 2018. 